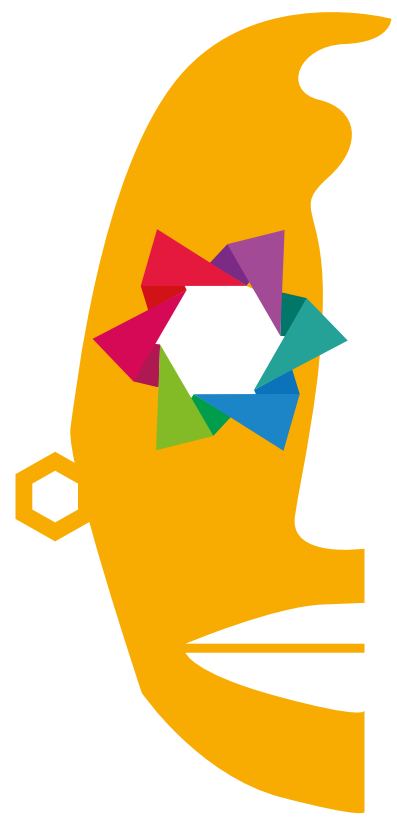

Olga Bezhanova

Universidad de Southern

Illinois en Edwardsville

EE.UU.

\title{
La sirvienta y el luchador (2011) y Moronga (2018) de Horacio Castellanos Moya
}

\section{La sirvienta y el luchador (2011) and Moronga (2018) of Horacio Castellanos Moya}

ReSUMeN

Este trabajo analiza dos novelas del escritor honduro-salvadoreño Horacio Castellanos Moya, La sirvienta y el luchador (2011) y Moronga (2018), y demuestra que la producción novelística del autor representa un todo complejo y abarcador donde los lectores se informan, no solo a través del texto de la obra, sino también por el hecho de acceder al espacio entre las novelas donde ocurren muchos de los eventos cruciales para la historia del istmo y las vidas de los personajes de estas obras. Aunque cada una de las obras escritas por Castellanos Moya se puede leer sin conocimiento previo de otras novelas suyas, la capacidad de los lectores de entender el valor y el sentido de cada obra se ve profundamente impactada por su acceso a los intersticios que se ubican entre las novelas.

Palabras clave: Literatura, El Salvador, Horacio Castellanos Moya, guerra civil salvadoreña

\begin{abstract}
This article analyzes two novels by the Honduran-Salvadoran writer Horacio Castellanos Moya, La sirvienta y el luchador (2011) y Moronga (2018), and demonstrates that the author's novelistic output represents a complex and all-encompassing whole. Readers glean information not only from the novels themselves but also from the space between these works of literature where many crucial historic events take place and the characters evolve. Each of Castellanos Moya's novels can be read and enjoyed without having read his
\end{abstract}


preceding work, yet the readers' capacity to understand the nuance of each novel is deeply impacted by whether they have been able to access the interstices between the two novels.

Keywords: Literature, El Salvador, Horacio Castellanos Moya, Salvadoran civil war

El escritor honduro-salvadoreño ${ }^{1}$ Horacio Castellanos Moya ha creado un universo complejo dentro de su producción artística en el que la lectura de cada una de las novelas enriquece y matiza la comprensión de las otras. Para dar un ejemplo, Moronga, la novela de Castellanos Moya que salió a la luz en 2018, oculta a los lectores primerizos la existencia de una relación familiar entre dos de los narradores en primera persona, José Zeledón y Erasmo Aragón ${ }^{2}$. Los lectores que han leído la novela del autor titulada La sirvienta y el luchador (2011) observarán que las dos primeras partes de Moronga (2018) son narradas por un tío y un sobrino quienes no son conscientes de la existencia de este lazo familiar. De esta manera, el hecho de conocer la novela anterior brinda la familiaridad con los aspectos de la obra que se quedan ocultos para los personajes de la misma. A la vez, un análisis de La sirvienta y el luchador (2011) y Moronga (2018) como partes de un conjunto proporciona un entendimiento de la metamorfosis que ha experimentado Centroamérica tras la clausura de los conflictos armados de las décadas de los '70 y ' 80 del siglo pasado. El desplazamiento del foco de la atención de Centroamérica a los Estados Unidos que se observa en la novela más reciente del autor constituye una de las innovaciones más marcadas dentro del corpus novelístico de Castellanos Moya y refleja la intensificación de la neoliberalización de la región y la consecuente destrucción de muchas de las categorías que estaban en el centro de la obra anterior del escritor, tales como, por ejemplo, el concepto del regreso a la patria desde el exilio (Wallace 2018) ${ }^{3}$ o la figura de un personaje femenino fuerte y heroico. Dichas transformaciones se ubican entre las dos obras y, como resultado, solo los lectores cuidadosos de ambas pueden darse cuenta de ellas. En este ensayo me propongo estudiar precisamente este espacio entre las dos novelas que está sugerido por ellas y que contiene las claves para la comprensión de los cambios que ha experimentado El Salvador entre 1980, el año cuando transcurre

1 Castellanos Moya nació en Tegucigalpa en 1957, pero su familia se mudó a El Salvador cuando el futuro escritor apenas tenía 4 años de edad. Aunque la mayor parte de su obra literaria se enfoca en la historia y en la realidad contemporánea de El Salvador, Castellanos Moya también ha escrito sobre Honduras y Guatemala y la historia trágica de estos países.

2 La novela está dividida en tres partes tituladas "Primera parte. Zeledón", "Segunda parte. Aragón” y "Epílogo. El tirador oculto". Las dos primeras partes son narradas, respectivamente, por Zeledón y Aragón mientras que el epílogo está introducido como "traducción libre, no oficial" $(2018,297)$ de un informe escrito por agente especial Donald P. Chiwaski quien describe en gran detalle un encuentro violento entre las fuerzas del FBI, los miembros de un cártel mexicano y unos exguerrilleros salvadoreños, quienes han puesto las destrezas adquiridas durante la guerra civil salvadoreña al servicio del narcotráfico.

3 El sueño del retorno (2013) es una de las obras de Castellanos Moya en las que el deseo del protagonista de regresar a El Salvador desde su exilio mexicano funciona como el resorte que pone en movimiento la trama novelesca. Cinco años más tarde, el mismo escritor insistió en una entrevista en que la idea del retorno había perdido su potencia para muchos salvadoreños y, por lo consiguiente, está ausente de Moronga (Wallace 2018). 
la acción en La sirvienta y el luchador (2011), y Moronga (2018) que se despliega entre el mayo de 2009 y el junio de 2010.

Castellanos Moya es, en las palabras de Emanuela Jossa "el escritor salvadoreño más conocido, leído, traducido y también discutido" de nuestros días (2019, 347). Según Alexandra Ortiz Wallner, la obra del escritor constituye un punto de referencia indispensable para cualquiera que tiene interés en entender la literatura centroamericana de los finales del siglo XX y los principios de siglo XXI (2009, 191). En un poco más de la década que ha transcurrido desde la publicación del estudio de Ortiz Wallner, Castellanos Moya ha consolidado su posición como uno de los escritores más destacados del istmo y ha logrado, con la publicación de su novela más reciente, consolidar un público más allá de lo que es usual para un autor centroamericano. En su reseña de Moronga (2018), Ronald Sáenz Leandro ha señalado que la novela ha abierto una nueva fase en la trayectoria artística y publicitaria del autor:

En términos comerciales, Moronga marca una nueva etapa editorial en la carrera de Horacio Castellanos Moya con Penguin Random House, luego de que la inmensa mayoría de su narrativa precedente publicada en España había estado ligada al sello editorial catalán Tusquets. $(2018,345)$

El hecho de haber atraído la atención de un conglomerado tan grande como Penguin Random House constituye un gran éxito para un escritor centroamericano, quien lleva ya más de dos décadas de residir fuera de El Salvador, pero quien nunca dejó de escribir novelas profundamente salvadoreñas que están impregnadas por el deseo apasionado del autor de entender la historia reciente y la realidad contemporánea del país ${ }^{4}$.

Mucho se ha dicho de la transformación experimentada por la literatura centroamericana tras el fracaso de los proyectos revolucionarios de la segunda mitad del siglo XX. Varios críticos literarios han debatido si resultan adecuados los términos como ‘el cinismo' o 'el desencanto' introducidos por Cortez (2009) para

$4 \quad \mathrm{Al}$ acabarse la guerra civil, Castellanos Moya regresó a El Salvador de su exilio mexicano con la meta de participar en la redefinición del proyecto nacional salvadoreño para adaptarlo a la nueva época de la paz y a la democracia que se vislumbraba tras 12 años del conflicto civil. La colección de ensayos publicada en 1993 bajo el título Recuento de incertidumbres: Cultura y transición en El Salvador nos deja entrever cómo concebía el escritor la visión de la nación salvadoreña que se iba a distinguir de los "dos proyectos de nación radicalmente distintos y excluyentes" que se enfrentaron durante la guerra civil (Castellanos Moya 1993, 15). Sin embargo, el escritor tuvo que abandonar el país de nuevo en 1997 al recibir amenazas de muerte que acompañaron la publicación de su novela El asco. Thomas Bernhard en San Salvador (Vides 2016, 22). Castellanos Moya ha vivido en varios países (Canadá, Alemania, Japón, México y los EE.UU.). En la actualidad, enseña en el departamento de español y portugués de la Universidad de Iowa. Sin embargo, siempre ha sido un escritor muy salvadoreño y sigue siendo indefectiblemente fiel a su proyecto vital de reflejar en su obra literaria las realidades dolorosas de su país de origen y, más recientemente, el destino de los salvadoreños desplazados para siempre de Centroamérica. 
referirse a las características básicas de la producción artística reciente de los escritores centroamericanos cuyas obras reflejan la pérdida de la fe en la capacidad de los movimientos izquierdistas armados de impactar la situación en la región de una manera positiva ${ }^{5}$. Kokotovic (2006), por ejemplo, encuentra útiles los términos como 'el desencanto' o 'la desilusión' para describir el estado afectivo en el que se encontraron muchos centroamericanos tras la firma de los tratados de paz que pusieron fin a las guerras civiles en la región y sugiere que la literatura creada en la posguerra está marcada, de una manera imborrable, por este estado de ánimo. Galindo-Doucette (2012), sin embargo, contradice la postura de Kokotovic (2006) e insiste en que resulta erróneo referirse a la obra de un escritor como Castellanos Moya como representativa de una visión desencantada de la realidad centroamericana, puesto que la idea misma del desencanto supone la existencia de un encanto previo que se llega a romper debido a una serie de circunstancias objetivas. Según señala Galindo-Doucette $(2012,553)$, en la novelística de Castellanos Moya "no hay evidencia de un encanto nacional previo" y, por lo tanto, el término "desencanto" no puede aplicarse a la obra literaria que surge en la posguerra centroamericana. Mientras que no se pueda, precisamente por las razones aducidas por Galindo-Doucette, hablar de la postura desencantada del novelista, es innegable que el corpus novelístico entero de Castellanos Moya expresa los sentimientos de toda una generación de centroamericanos, quienes fueron impactados por la incapacidad de los movimientos revolucionarios de detener la marcha triunfal del neoliberalismo en la región. El desencanto se halla no tanto en la cosmovisión de Castellanos Moya, como en la de muchos de los lectores que se ven atraídos por su obra.

El escritor honduro-salvadoreño ha expresado, en términos claros, su actitud hacia el hecho de haberse convertido, gracias a los esfuerzos de los estudiosos de la literatura centroamericana, quienes han insistido en la centralidad del cinismo o la desilusión para su obra, en uno de los autores claves de la 'literatura del desencanto'. En una entrevista otorgada a Lilian Fernández Hall, en el 2009, Castellanos Moya rechazó la idea de que su labor literaria estuviera impregnada del cinismo y señaló que una actitud del desengaño, si tal hay en su obra, no proviene de una posición de una generación desilusionada con la totalidad de la realidad centroamericana sino de un rechazo a ciertos aspectos existentes en las sociedades de la región que se plasmaron en las últimas tres décadas:

Yo pertenezco a la generación que protagonizó la guerra civil, una generación que no se fue a la guerra por cinismo sino precisamente por lo contrario, por

5 Seoane (2019) ofrece un excelente resumen de las aportaciones críticas a la discusión del término 'literatura del desencanto' y anota, de una manera acertadísima, que "el desencanto puede ser también un efecto de recepción" (95), dado el hecho de que el lector que se siente atraído por la obra como la de Castellanos Moya ya de por sí está dispuesto a acercarse a la realidad centroamericana de una manera bien específica. 
la creencia en la posibilidad del cambio, por la voluntad de hacer ese cambio. Después de la guerra algunos de nosotros escribimos novelas con protagonistas desencantados ante la nueva sociedad. Pero hacer una generalización a partir de ello es convertir la parte en el todo.

Claro está, los que leemos y analizamos la novelística de Castellanos Moya no tenemos obligación alguna de aceptar a cierra ojos el juicio del autor acerca del significado de su propia obra. Sin llegar a los extremos de restar toda importancia a la intención del autor que fueron demolidos por el trabajo hoy ya clásico de Hirsch (1967), podemos acercarnos a obras literarias a partir de las sensaciones que nos provocan y las ideas que nos inspiran como el criterio básico que informa nuestro juicio de ellas en vez de dar siempre prioridad a la intención del autor. Desde este punto de vista, no es de extrañar que muchos lectores y críticos llegaran a la conclusión de que las novelas de Castellanos Moya de hecho se caracterizan por una falta de la fe en la capacidad de la lucha armada de acarrear cambios políticos, económicos y sociales que tanta falta hacen en la región. Cada lector ya decidirá por su propia cuenta si esta actitud debe considerarse cínica o más bien realista.

La falta de la fe en el proyecto del cambio radical político y social a través de la lucha revolucionaria, que anima la escritura de Castellanos Moya desde su primera novela La diáspora (1988), no le resta dimensiones profundamente políticas a la obra del escritor. Quirós (2010) y Coello Gutiérrez (2014) plantean la existencia de importantes vertientes políticas en la novelística de Castellanos Moya y otros escritores de la posguerra centroamericana, que corresponden a las urgencias del momento en que se publican estas obras y que se distinguen radicalmente de la época anterior. Según Perkowska y Zavala (2018), tanto los temas que aborda Castellanos Moya como el lenguaje que emplea en su obra tienen "un potencial político porque al sacudir el saber y el sentir del lector abre un espacio para el cuestionamiento de la realidad desde la que éste lee y piensa" (11). Lo que los críticos a veces dejan de tomar en cuenta en su análisis de 'la literatura del desencanto' es que el hecho de hablar de la pérdida de vigencia de lo político en una sociedad neoliberal ${ }^{6} \mathrm{es}$, de por sí, una de las pocas acciones capaces de efectuar cambios reales. Al respecto anota

$6 \quad$ El neoliberalismo es un concepto que no se presta fácilmente a una definición abarcadora y exhaustiva. Se han ofrecido tantas definiciones distintas y a veces contradictorias del término que Leary (2018) observó jocosamente en la introducción a su glosario del vocabulario usado por los partidarios del pensamiento neoliberal que el neoliberalismo es una palabra que se usa para referirnos a todo lo que nos disgusta en la realidad del momento en el que se vive (13). Hay un consenso crítico generalizado, sin embargo, que el sistema neoliberal se basa en la introducción de los principios del funcionamiento de los mercados en todas o casi todas las esferas de la actividad humana, lo que llega a transformar la manera en que los individuos se relacionan con el mundo y conceptualizan su propia existencia (Dardot y Laval 2013, Ventura 2012). Castellanos Moya es uno de los escritores centroamericanos cuya obra está impregnada, en la misma medida, por una desilusión profunda con el izquierdismo y una crítica feroz al modelo económico neoliberal (Kokotovic 2006). 
Jossa (2019) que "en la narrativa del escritor salvadoreño se advierte una voluntad de intervención política que se realiza dentro de la escritura para moverse hacia fuera, hacia una lectura que sea impugnación, disputa, cuestionamiento" (349). Cuesta reconocer la voluntad de Castellanos Moya de intervenir de una manera productiva en el funcionamiento de la sociedad es porque hacemos uso de las definiciones que animaron la lucha armada de los años setenta y ochenta en Centroamérica, pero que ya no se aplican a la realidad del momento en que vivimos. Lo que queda claro, ya que han pasado casi tres décadas desde la clausura del conflicto civil en El Salvador, es que, lejos de ser puramente cínicas, como se ha sugerido anteriormente, las novelas de Castellanos Moya y de la generación de los escritores centroamericanos a la que pertenece ${ }^{7}$ se basan en la definición de lo político que tiene vigencia en nuestro momento histórico y se distingue de una manera radical de la que existió antes del triunfo del neoliberalismo a la escala mundial. Como señala a propósito Barchino (2007),

la realidad nacional ha cambiado y las nuevas novelas se mueven en un territorio ideológico, histórico y social muy distinto de las que se escribieron en los años del conflicto salvadoreño y los inmediatamente anteriores. De hecho, las ficciones narrativas - pese a la pérdida de sus afirmaciones revolucionariashan sido barómetros puntuales de los cambios sociales y políticos que se han operado en la sociedad salvadoreña y en otros países centroamericanos de la última década. (6)

Castellanos Moya siempre ha insistido en la importancia de las dimensiones sociales de su proyecto narrativo. En la entrevista otorgada a Rodríguez Freire el mismo año que se publicó La sirvienta y el luchador, el escritor habló del asunto de la siguiente manera: "En mi literatura lo político es el paisaje de fondo, es lo que permea las situaciones en las que los personajes sufren sus problemas vitales... Se pueden encontrar afectados por la política y a veces determinados por ella" (2011, 65). En La sirvienta y el luchador (2011) y Moronga (2018), las novelas analizadas en este ensayo, podemos ver cómo las vidas humanas se transforman y se moldean por los eventos históricos que les toca experimentar.

La sirvienta y el luchador (2011) pertenece a la serie de novelas escritas por Castellanos Moya que narran la historia de El Salvador desde los años 1940 hasta nuestros días a través de las peripecias de la familia Aragón. Las novelas pertenecientes a esta serie que se han publicado hasta ahora son Donde no estén ustedes (2003), Desmoronamiento (2006), Tirana memoria (2008), La sirvienta y el luchador (2011), El sueño del retorno (2013) y Moronga (2018). Al mismo tiempo,

7 Entre los escritores salvadoreños quienes a menudo se nombran como representantes de 'la literatura del desencanto’ se destacan Rafael Menjívar Ochoa, Jacinta Escudos, Claudia Hernández y Miguel Huezo Mixco (Galindo-Doucette 2012, 565, n. 1). 
en varias de las obras publicadas por el autor que no pertenecen a la serie Aragón (tales como, por ejemplo, La diabla en el espejo (2000) y El arma en el hombre (2001)) se encuentran unos personajes que, de una manera tangencial, aparecen en las novelas que tratan de la familia Aragón, lo cual permite hablar de un universo narrativo coherente, aunque fraccionado, creado por Castellanos Moya.

La naturaleza profundamente fragmentada del universo narrativo de Castellanos Moya observada por Buschmann (2013) se debe a las rupturas que ocurrieron en el espacio político y cultural salvadoreño como resultado de la guerra civil. Las dificultades experimentadas por los que disfrutamos de la obra de Castellanos Moya a la hora de tratar de entender los vínculos entre los personajes que aparecen y desaparecen, dejando rastros que se tienen que trazar sin nunca saber si se está en posesión de toda la información pertinente para entender lo que ocurre, reflejan la postura de los que han vivido la situación salvadoreña como parte de su experiencia vital (Sarmiento 2016).

La acción en La sirvienta y el luchador (2001) transcurre en 1980, el año clave en la historia de El Salvador, cuando se agudizaba el conflicto entre el gobierno derechista del país y los guerrilleros izquierdistas pertenecientes al Frente Farabundo Martí para la Liberación Nacional (FMLN). La novela está protagonizada por María Elena, la criada de la familia Aragón quien solicita la ayuda de su antiguo pretendiente Vikingo, un policía político involucrado en la tortura de prisioneros, para enterarse de la suerte de Albertico Aragón, secuestrado y matado como resultado de sus ideas consideradas subversivas. El título de la obra se refiere a la relación entre María Elena y el Vikingo, un torturador fiel al régimen, quien de joven era un luchador conocido y nunca logró olvidarse de sus antiguas glorias atléticas.

En sus desplazamientos por la capital del país, que se ve engullida en la lucha cada vez más violenta entre la dictadura y los revolucionarios, María Elena se da cuenta de que su nieto Joselito, un estudiante de ingeniería "callado y estudioso" (Castellanos Moya 2011,52) está involucrado en las actividades clandestinas de la guerrilla, aunque él mismo todavía no ha pasado a la clandestinidad y sigue viviendo con su madre y abuela. El apabullamiento experimentado por María Elena al darse cuenta de que todo lo que le parecía tan seguro y formaba el fundamento de su vida - su papel de una empleada de la familia rica y poderosa de Aragón, los éxitos profesionales de su hija Belka y su fe en el futuro seguro y cómodo de su nieto-se está desmoronando frente a sus ojos en un torbellino de eventos, cuyo significado María Elena no logra descifrar. María Escobedo caracteriza La sirvienta y el luchador (2011) como "una narrativa trepidante. . en la que los episodios impactantes se suceden a una velocidad de vértigo gracias a la fuerza de unos diálogos rápidos y contundentes que a menudo suenan como latigazos en el oído del lector" $(2011,131)$. Esta manera de narrar los sucesos que ocurrieron 
en El Salvador en las vísperas de la guerra civil sumerge al lector en el estado de ánimo cercano al de los personajes de la obra, quienes se sienten abofeteados por los hechos que se desarrollan alrededor suyo con una rapidez apabullante.

A lo largo de la primera parte de la novela, los lectores perciben la situación a través de las experiencias de María Elena y Vikingo, narradas en el estilo indirecto libre que les abre una ventana hacia el mundo interior de estos personajes. Al empezar la segunda parte de la obra, la perspectiva se desplaza para dejarles a los lectores conocer el punto de vista de Joselito a través del mismo estilo narrativo. Al hablar del discurso indirecto libre, Bueler (2001) ha señalado que el uso de este modo narrativo obliga a los lectores a adentrarse en las emociones experimentadas por los personajes que, a menudo, resultan demasiado rudimentarias e indefinidas para que los personajes mismos las puedan expresar de una manera directa. En esta época de su vida, Joselito todavía no sabe cuáles de los rasgos que conforman su personalidad en este momento de la temprana juventud van a jugar el papel central en su vida adulta. Las técnicas narrativas empleadas por Castellanos Moya permiten a los lectores vislumbrar el futuro que espera a Joselito, pero solo la lectura de Moronga (2018), una novela publicada siete años más tarde, ofrecerá la respuesta definitiva a la pregunta de cómo impacta la realidad trágica de El Salvador engullido por la guerra civil a los jóvenes, quienes, como Joselito, deciden combatir la injusticia que domina la sociedad salvadoreña y se unen a la guerrilla.

El acercamiento inicial de los lectores de la obra al mundo interior de Joselito confirma la impresión creada por las descripciones del joven proporcionadas por María Elena que lo caracterizan como un chico casero y bastante inocente ${ }^{8}$. Sin embargo, ya en estas fechas tempranas, tras la fachada de un joven tímido y estudioso, María Elena, quien tiene la mala suerte de toparse con su nieto cuando Joselito lleva a cabo una de las operaciones clandestinas más audaces en las que ha podido participar hasta el momento, empieza a vislumbrar "un destello de ferocidad que ella no le conocía" (197). Es precisamente este hombre feroz y desalmado quien protagonizará, años más tarde, Moronga (2018), la novela de Castellanos Moya que revela la trayectoria vital de este personaje tras su decisión de abandonar su familia y dedicarse por completo a la lucha clandestina que ciera La sirvienta y el luchador (2011).

8 Para dar un ejemplo, en el medio de su inmersión, siempre más intensa, en las actividades de la célula en la organización guerrillera a la que pertenece, Joselito no deja de pensar en las disculpas que le ofrecerá a su abuela si llega tarde a cenar por culpa de sus compromisos guerrilleros (Castellanos Moya 2011). Tras tropezar con María Elena en medio de una operación secreta, Joselito se angustia por la posibilidad de que su abuela cuente lo sucedido a Belka, la madre del joven (Castellanos Moya 2011). 
María Elena se queda atónita al enterarse de la vida clandestina de su nieto, pero, al adentrarse en el mundo interior de la antigua sirvienta de la familia Aragón, los lectores se percatan de que ella también guarda unos secretos que nunca le ha revelado a nadie. En su última conversación con el Vikingo, María Elena se percata de que el asesinato de don Clemente Aragón, un evento que juega un papel crucial para el argumento de varias novelas de la serie Aragón, se produjo como resultado de su deseo de ocultar la naturaleza de su relación con don Clemente y mantener en secreto el hecho de que este fuera el padre de su única hija Belka. La incapacidad de los personajes de La sirvienta y el luchador (2011) de sincerarse y llegar a confiar en otro ser humano se produce como resultado de vivir en una sociedad escindida en dos bandos en la que callarse constituye la única posibilidad de la supervivencia. Así han descrito Rojas y Ovares (2018) el impacto de la situación política del país en la manera en que interactúan los personajes de la novela:

En una situación de guerra que divide la sociedad en dos bandos todos esconden información sobre los hechos y las identidades. Casi todos los personajes callan lo que sucede y no revelan lo que saben, sino que guardan información y ocultan una identidad secreta. El trabajo político de la clandestinidad se basa en el secreto, como el caso de Joselito; este no cuenta ni a su madre ni a sus compañeros que su abuela lo descubrió como militante. Al Vikingo lo mortifica el secreto de María Elena y a ella, como a los integrantes de la familia Aragón, la identidad del asesino de uno de sus integrantes. . María Elena y Belka, por otro lado, no revelan quiénes son los padres de sus respectivos hijos; esta última tampoco habla de su relación con Barrientos, ayudante de los militares; María Elena no da toda la información a la familia Aragón ni con respecto a Clemen ni acerca de lo que sabe del secuestro de Albertico.

Los lectores de La sirvienta y el luchador (2011) se ven obligados a reunir la información que, gota a gota, proporcionan varios personajes de la novela y así pueden percatarse, aunque sea de una manera mínima y distante, de cómo se sienten los que se encuentran en medio de una sociedad como la salvadoreña durante la guerra civil.

En su análisis de la representación de los movimientos guerrilleros centroamericanos en la obra de Castellanos Moya, Basile (2015) hace uso del concepto de 'memorias perturbadoras' desarrollado por Portelli (2013) para señalar la importancia, dentro del corpus literario de Castellanos Moya, del cuestionamiento efectuado por el autor de varios aspectos problemáticos de estos movimientos, tales como,

la teoría del foco, las relaciones entre los medios y los fines, el vínculo entre la violencia y la política, las diferencias entre el socialismo real y el imaginado, la peculiaridad de los contextos político sociales en América Latina, el menosprecio de la izquierda revolucionaria por el sistema democrático, la estrecha 
concepción del Estado como un mero aparato de represión, el rechazo de la política, la "ensalada ideológica", el aislamiento de las masas, el verticalismo y autoritarismo de los cuadros dirigentes y su falta de diálogo interno, el desprecio por el mundo de la vida privada, la familia, los afectos y emociones frente a la valoración de la militancia. (Basile 2015, 3-4)

En su ensayo, Basile se enfoca en la obra del escritor publicada anteriormente a La sirvienta y el luchador (2011) y Moronga (2018) ${ }^{9}$. Sin embargo, es precisamente en el espacio entre estas dos novelas donde la crítica de la izquierda revolucionaria señalada por Basile (2015) cobra sus dimensiones más amplias, puesto que es allí donde ocurre la transformación de Joselito Hernández, un joven idealista y sincero, en José Zeledón, el protagonista de Moronga (2018), un hombre cínico y despiadado, quien actúa de una manera extremadamente violenta y cruel sin un más mínimo asomo de interés por lo político. La naturaleza de las organizaciones guerrilleras centroamericanas descrita por Basile (2015) se puede vislumbrar en los pocos recuerdos de su vida en la guerrilla que Zeledón no logra reprimir por completo y que lo atormentan a lo largo de su estancia en Merlow City, donde su tarea principal consiste en ocultar de la gente que lo rodea su pasado en la guerrilla y, más tarde, en el narcotráfico.

Mansilla (1990) define la violencia como "la renuncia a la comunicación oral, a la que es inmanente la probabilidad de una confrontación corporal inmediata; se manifiesta mayormente en la consecución física de pretensiones y expectativas definidas unilateralmente" y demuestra cómo este abandono del diálogo condiciona "las pautas de pensar y de comportarse de los partidarios de la guerrilla" en Latinoamérica (119). La parquedad oral de Zeledón, quien inclusive en la intimidad se expresa con frases extremadamente cortas, apunta hacia la pérdida de confianza en el diálogo que experimenta este personaje como resultado de sus experiencias guerrilleras.

Moronga (2018) se abre con la narración en primera persona efectuada por un personaje quien se introduce como José Zeledón, pero desde el principio de su narrativa nos deja saber que ni él ni Rudy, su antiguo compañero de la guerrilla, en la actualidad usan sus nombres verdaderos. "Ni él ni yo recuperaríamos jamás nuestros nombres originales. Nada tenían que ver ya con nosotros", dice Zeledón al enterarse del nuevo apodo de su antiguo compañero $(2018,15)$. La adopción frecuente de nombres diferentes por parte de Zeledón y Rudy no solo señala que se trata de individuos que viven en la clandestinidad casi dos décadas tras la firma de los Acuerdos de Paz de Chapultepec ${ }^{10}$, sino también sugiere que estos perso-

9 No es de extrañar que sea así, puesto que Moronga (2018) salió a luz tres años tras la publicación del estudio de Basile (2015) y es solo al acercarse a La sirvienta (2011) y Moronga (2018) como dos partes de un todo abarcador que se esclarecen estos aspectos de las dos novelas.

10 La acción en la parte de la obra narrada por Zeledón transcurre entre el agosto de 2009 y el mayo de 2010. 
najes han experimentado una pérdida de la identidad que los ha desplazado por completo de la manera de ser a la que se asociaban sus nombres verdaderos. Hace mucho que acabó la guerra civil salvadoreña, pero los protagonistas de Moronga (2018) todavía no conciben la posibilidad de dejar al lado las costumbres aprendidas en la clandestinidad ${ }^{11}$.

Según Buschmann (2013), los personajes de Castellanos Moya comparten una experiencia de fracaso y de la incapacidad de adaptarse a la realidad de la posguerra salvadoreña. La inadaptación que comparten con muchos de los protagonistas de la novela centroamericana de la posguerra funciona como

una alegoría de la situación de toda una generación de centroamericanos que no han aprendido más que el oficio de la guerra y que se enfrentan a las nuevas condiciones de la posguerra y a su inserción en la vida civil- (Mackenbach \& Ortiz Wallner 2008, 88)

Aunque José Zeledón y Erasmo Aragón son tío y sobrino, los dos desconocen este vínculo familiar y se desenvuelven en capas sociales diferentes, lo cual, sin embargo, no cancela el hecho de que sufran de la misma incapacidad de insertarse en la sociedad estadounidense que se debe al trauma de la guerra.

El cambio que ocurre en cuanto al papel que los personajes femeninos representan en La sirvienta (2011) y Moronga (2018) refleja el hecho de que muchos de los avances alcanzados por las mujeres como resultado de su participación en los movimientos de protesta antes y durante la guerra civil fueron borrados tras la clausura del conflicto armado (Kokotovic 2006, 18-9). Ya al nivel de los títulos de las dos obras se puede vislumbrar el desplazamiento de lo femenino por una versión agresiva y profundamente patriarcal de la masculinidad que acompaña el surgimiento de las maras como el fenómeno que tiene un grave impacto en la seguridad de la mujer salvadoreña. No fue hasta 2003 que las matanzas de las mujeres en El Salvador empezaron a incluirse en las estadísticas anuales como una categoría aparte dentro del número total de homicidios, pero sabemos que entre 2003 y 2015 la cifra de las víctimas femeninas por 100,000 personas subió de 7,4 a 16,79 (Musalo 2018,39). Este trágico aumento se atribuye a la intensificación de la violencia intrafamiliar y las actividades de las maras (Musalo 2018, 41). Las pandillas que devastan los países del Triángulo Norte constituyen focos de abuso y violación que irradian estas prácticas a todos los ambientes donde se desenvuelven sus miembros (Obinna 2021, 807-8). El Salvador, que según Dudley

11 José Zeledón, por ejemplo, siempre se sienta en el asiento trasero del bus para así evitar que nadie se le acerque desapercibido y dedica mucho tiempo a escudriñar en Google Maps y Google Earth las rutas que piensa usar para trasladarse por las ciudades estadounidenses donde se encuentra (Castellanos Moya 2018, 67). Igualmente, Aragón - a pesar de que nunca experimentó el combate y solo apoyó a la guerrilla a través de la labor periodística en su exilio mexicano-vive "como quien se sabe todo el tiempo vigilado" $(2018,291)$. 
(2011, 83) es "el corazón espiritual" del fenómeno marero en Centroamérica, es también el país donde más ha avanzado el proceso de la compenetración entre estas organizaciones criminales y los cárteles de drogas. El contraste entre La sirvienta (2011) y Moronga (2018) refleja el surgimiento de esta nueva realidad y su impacto en la situación de la mujer en la región. En la novela anterior, el punto de vista del luchador Vikingo se contrapesa por la perspectiva de María Elena, mientras que el título de Moronga (2018) remite no solo al apodo de uno de los personajes sino al término que, en Centroamérica, se usa para referirse a la morcilla y, a la vez, al órgano sexual masculino.

Al nivel textual, la mujer centroamericana en la novela más reciente de Castellanos Moya aparece como una presencia malévola y destructiva, lo cual ofrece un marcado contraste con la visión de lo femenino que vemos en La sirvienta (2011). Mientras que El Salvador sucumbe a una lucha fratricida (o más bien, matricida, en el caso de Joselito), María Elena es el único personaje quien nunca traiciona sus principios. Al sufrir en persona la violencia generada por los choques entre las fuerzas del gobierno y los guerrilleros, se queda fiel a su visión personal de lo bueno y lo malo. El comportamiento abnegado y valiente de la antigua criada de la familia Aragón hace de ella la única heroína de la novela. La sirvienta (2011) describe una realidad donde todavía hay lugar para una figura femenina indomable, lo cual no es cierto en cuanto a la novela más reciente.

En Moronga (2018) no hay mujeres de la talla de María Elena. El único personaje femenino centroamericano que aparece en la obra de una manera más que tangencial es Amanda María Packer, una niña guatemalteca adoptada por una pareja norteamericana que la trata como si fuera un objeto de consumo y nunca pondera las razones del comportamiento violento y extremadamente sexualizado de la niña (Bezhanova 2020, 223). La historia trágica de Amanda pone de relieve el legado de las relaciones entre Latinoamérica y los Estados Unidos durante la Guerra Fría cuando varios países latinoamericanos funcionaron como el espacio para poner en práctica los elementos de la naciente economía neoliberal (Salinas Figueredo 2007). Así postula Mariana Calvento las características básicas del neoliberalismo: "Las principales variables de la corriente neoliberal centraban, y centran, su atención sobre una concepción individualista del ser humano y sobre un papel privilegiado del mercado sobre la sociedad" (2006, 57). El triunfo de este sistema de las relaciones económicas en Centroamérica fue consolidado justamente entre las épocas descritas en La sirvienta (2011) y Moronga (2018). Sus efectos se pueden observar en la desaparición de los personajes generosos y desinteresados, como María Elena, y surgimiento de los que, como Amanda y sus padres adoptivos, ven a los demás nada más que como un instrumento que pueden usar para autocomplacerse. De esta manera, Castellanos Moya ofrece, en su obra, 
una crítica feroz de los que se guían por una visión neoliberal del valor de un ser humano. Según anota al respecto Quirós (2010),

lo que parece a veces sólo una representación literaria de cinismo y sociedades plagadas por corrupción, violencia y criminalidad, se podría también interpretar como una importante respuesta crítica ante el intento del capitalismo neoliberal de constituirse como la única lógica social, política y económica, especialmente dada la caída del proyecto izquierdista a nivel regional y global. (2)

Por mucho que Zeledón se esfuerce por reprimir toda memoria de su pasado guerrillero y de su vida como Joselito Hernández, el encuentro con su antiguo compañero de lucha apodado el Viejo trae de vuelta los recuerdos que le gustaría sepultar para siempre en el olvido. Los breves apartados de la novela dedicados a los recuerdos de la guerra civil, que atormentan a Zeledón tras su cita con el Viejo, funcionan como puntos de contacto entre Moronga (2018) y La sirvienta y el luchador (2011). En el camino de regreso a Merlow City después de su encuentro con el Viejo, Zeledón rememora el momento durante una ofensiva de la guerrilla que lo lleva hasta la capital del país. Al hallarse en el edificio donde solía vivir con su madre y su abuela y donde se desarrolla parte de la acción de La sirvienta (2011), Zeledón se da cuenta del abismo que lo separa del joven que solía ver este edificio como su única casa:
Al cuarto día de la ofensiva instalé el puesto de mando en la planta baja del edificio de apartamentos donde había transcurrido toda mi vida, hasta que me fui a la clandestinidad y luego al monte. Sentí muy extraño. No había vuelto desde entonces. 'En este apartamento viví yo,' le dije al Viejo, señalando hacia la cuarta planta. (72)

El segundo fragmento de sus memorias guerrilleras que Zeledón recupera tras su encuentro con el Viejo en Chicago parece cumplir la función de justificar, en los ojos del propio Zeledón, su amistad duradera con este hombre, a quien sus comandantes en la guerrilla se referían como "un asesino exconvicto" y quien nunca mostró el más mínimo interés por nada que tuviera que ver con la política o las ideas revolucionarias de los guerrilleros $(2018,83)$. Zeledón rememora el momento durante la guerra civil cuando el Viejo mató a un capitán guerrillero quien abusaba sexualmente de los niños del campamento y había urdido una trama para asesinar a Catarina, la novia de Zeledón. Tras la guerra, los exguerrilleros se suman a lo que Zeledón caracteriza como "la nueva operación [en el] campo de amapolas en el altiplano guatemalteco" (Castellanos Moya 2018, 84), pero Zeledón parece querer reconfortarse con la memoria de un momento cuando el Viejo se comportó de una manera que podría calificarse como noble. Zeledón nunca comenta la pérdida de sus ideales políticos y tampoco revela cómo ha podido justificar la metamorfosis que culminó en su decisión de prestar sus servicios a un 
cártel de drogas, pero los lectores pueden entrever cierta incomodidad respecto a dicha transformación en su manera de referirse a su trabajo para los narcos como una 'nueva operación', como si no hubiera diferencia alguna entre su lucha revolucionaria y las actividades criminales del cártel.

En este contexto, cobra una importancia aún más profunda el momento cuando Zeledón intenta rememorar el día en el que se enteró del asesinato del arzobispo de San Salvador, monseñor Óscar Romero. Para muchos jóvenes de la época, tanto las enseñanzas del arzobispo como su asesinato por las fuerzas militares del estado salvadoreño en 1980 sirvieron como un despertar político que llevó a muchos de ellos a la lucha guerrillera (Cuéllar 2015, 155; Kampwirth 2010, 68-9). A Zeledón, sin embargo, le resulta imposible recordar qué hacía y en qué pensaba en el momento cuando escuchó la noticia de este asesinato que marcó, de una manera profunda, el destino de su país porque un poco antes había recibido noticias de una muerte que tenía un importe mucho más personal para él. La muerte de su madre Belka - cuyo nombre junto con su historia queda oculto para los lectores de Moronga (2018) que no conocen el texto de La sirvienta y el luchador (2011) —ocurrió como resultado de un ataque llevado a cabo por la célula a la que perteneció el mismo Joselito Hernández. Puesto que este es el mejor tirador de su grupúsculo subversivo, queda poca duda de que Joselito sea el combatiente quien da el tiro fatal que ocasiona la muerte de Belka, matada tras acompañar a su amante doctor Barrientos a una casa secreta donde la policía detiene y tortura a un guerrillero preso. El joven abandona su casa para pasar a la clandestinidad sin haberse enterado de la muerte de su madre ni concebir la más mínima sospecha del grave importe de su participación en un asalto a un Land Rover con vidrios polarizados que, como bien saben los lectores de La sirvienta (2011), resulta en la muerte de Belka. Mackenbach y Ortiz Wallner (2008) han postulado la violencia como el eje organizador de la novela centroamericana de las últimas décadas. En La sirvienta y el luchador (2011) y Moronga (2018) el asesinato, por parte de Joselito, de su propia madre simboliza la calidad sumamente íntima de los actos de agresión que ocurren durante las guerras civiles, puesto que este tipo de conflictos bélicos a veces convierte en enemigos a los compañeros e inclusive miembros de la misma familia.

Zeledón descubre su culpabilidad en la muerte de su madre en el espacio entre las dos novelas donde ocurre una gran parte de su desarrollo personal. Este momento trágico en la vida de Zeledón se alude en uno de los episodios en el que este no logra reprimir por completo las memorias dolorosas de la guerra civil que lo atormentan a lo largo de la obra. Al ver fracasar, uno tras otro, sus intentos por inscribirse en la vida pacífica y al darse cuenta de que no le queda otra opción que volver a reanudar los vínculos que lo unen con el Viejo, Zeledón está asediado 
por el rencor y no logra reprimir la memoria de "lo que nunca debí haber sabido" $(2018,100)$ sobre la muerte de su madre. En su última conversación con el Viejo, Zeledón intenta explicarle a su antiguo compañero en la guerrilla la razón por la que no quiere volver a involucrarse con el narcotráfico: "Más podrido estaría con tus nuevos patrones. Ya sabés que no me gustan. Yo me formé para accionar sabiendo quién era el enemigo. Todo muy claro. Había un sentido, una causa" $(2018,133)$. Al enterarse de que su madre fue una de sus primeras víctimas en el combate revolucionario, el hecho que, se repita, ocurre en el tiempo transcurrido entre las dos novelas, Zeledón se ve obligado a reconocer que su fe en la posibilidad de alcanzar la certeza completa de poder distinguir entre amigo y enemigo constituyó uno de los errores más grandes de su vida. El matricidio perpetuado sin querer por Joselito simboliza las heridas severas, y posiblemente fatales, que la guerra civil causa a la madre patria del pueblo salvadoreño y, a la vez, señala unas pautas para la comprensión de la ausencia del principio femenino positivo en la obra reciente del escritor. José Zeledón se encuentra desarraigado no solamente de su familia, que él mismo destruyó sin querer, sino también expulsado para siempre de su país de origen. Zeledón no parece tener descendientes, mientras que su sobrino Aragón mantiene escaso contacto con su hija, lo cual plantea la pregunta si la saga familiar de los Aragón acabará con estos personajes.

El trauma de la guerra civil se agravó como resultado de la incapacidad de los gobiernos democráticos de encontrar una manera de incorporar a muchos de los excombatientes y los intelectuales que apoyaron la guerrilla (como Aragón y el propio Castellanos Moya) en la vida productiva del país. Lejos de agradar a todos los excombatientes, la transformación de FMLN de una guerrilla a un partido político efectivo y poderoso dentro del contexto nacional fomentó sentimientos de desánimo y desilusión entre muchos de los antiguos guerrilleros, en especial los que nunca gozaron de altos cargos en la organización (Sprenkel 2018, 3-4). Zeledón ofrece un claro ejemplo de la indiferencia de muchos de los antiguos farabundistas de mediano y bajo rango a la victoria electoral de FMLN en los comicios de 2009. Se niega a compartir el júbilo de su amigo Rudy, quien se siente esperanzado al recibir las noticias de que Mauricio Funes logra "encaramarse a la Presidencia tras ganar las elecciones" $(2018,17)$. Los lectores no se enteran de los momentos precisos en que Zeledón pierde su interés por la política, pero su desvinculación de la causa a la que sacrificó su juventud y su familia es una clara señal de que muchas de las categorías que eran centrales para los salvadoreños en los años ochenta del siglo pasado se han vaciado del contenido.

La última parte de Moronga (2018) está narrada por el agente especial Donald P. Chiwaski y representa un informe sobre una balacera que toma lugar en Chicago en 2010 y en la que, sin nunca llegar a saberlo, se enfrentan Erasmo Aragón, quien 
actúa bajo las órdenes del FBI, y José Zeledón, a quien los agentes especiales a cargo de la investigación solo conocen como 'el tirador oculto'. En la balacera se cruzan de una manera violenta miembros de la misma familia salvadoreña, lo cual permite concluir que la última parte de la novela representa una recreación simbólica de la guerra civil salvadoreña en el territorio de la Estados Unidos, el país que dio pábulo a varias conflagraciones de este tipo en Centroamérica durante la época de la Guerra Fría (Bezhanova 2020). La naturaleza fratricida del conflicto bélico civil está simbolizada por el hecho de que Erasmo Aragón y José Zeledón, relacionados por el lado de Clemen Aragón, el tío de Erasmo y el abuelo de José, se encuentren - aunque sea a regañadientes y por falta de mejores opciones - en los lados enfrentados del conflicto. A pesar de haber rechazado la propuesta de El Viejo de participar en un asalto a un narcotraficante guatemalteco apodado Moronga, Zeledón recapacita y se presenta en el sitio acordado para el asalto donde acaba siendo el único participante quien logra salir indemne del tiroteo. Los agentes especiales quienes investigan el caso nunca se enteran de la identidad del tirador oculto, puesto que este se fuga tras la refriega sin dejar pistas. Los lectores de La sirvienta y el luchador (2011), sin embargo, poseen una clave para descifrar quién es el tirador oculto. Desde sus primeras operaciones en la célula revolucionaria, Joselito Hernández evidenció sus grandes dotes de francotirador al matar con un solo disparo al policía que perseguía a él y sus compañeros tras uno de los ataques efectuados por ellos (Castellanos Moya 2011, 148), y es precisamente este talento mortífero que salva su vida y le garantiza la libertad durante el asalto en Chicago treinta años más tarde. Una vez más, el hecho de conocer la obra anterior del escritor transforma por completo la capacidad de los lectores de entender el pleno significado de Moronga.

En la novela de la posguerra centroamericana lo nacional pierde vigencia (Escamilla 197), poniendo de relieve el triunfo de los principios de la globalización neoliberal en la región. Las fronteras entre los países no constituyen un serio obstáculo a los flujos de capital y mano de obra, lo cual socava los principios de la soberanía y debilita el poder de los gobiernos de los estados que carecen de un alcance hegemónico (Castillo Fernández 6). Las actividades de las organizaciones criminales transnacionales, tales como los cárteles y las maras, asimismo ponen en duda la capacidad de las agencias estatales de mantener su monopolio sobre la violencia dentro de la sociedad (Manwaring 2007, 48). Este proceso se intensifica entre las fechas de la publicación de las dos obras, culminando en el hecho de que Moronga (2018) resulte siendo la primera novela del autor donde la acción transcurre fuera de Latinoamérica y se desenvuelve en un ambiente angloparlante al que los personajes de la obra tienen que adaptarse en el sentido no solo puramente lingüístico sino también cultural. Mientras que la acción en La sirvienta (2011) se desarrolla en El Salvador y se relaciona a 
la problemática profundamente centroamericana, en la novela más reciente se observa el desplazamiento del foco del interés tanto del autor mismo, como de sus personajes, hacia los Estados Unidos. En una entrevista otorgada por Castellanos Moya tras la publicación de Moronga (2018), el escritor indica que El Salvador, Guatemala y Honduras son, en el momento de hoy, "estados incapaces: no fallidos sino tullidos ... que no le pueden ofrecer nada a su población, como no sea que salgan corriendo hacia EE.UU." (Wallace 2018). La violencia que está arrasando la región es, según el novelista, un mecanismo que facilita la "expulsión de la población hacia Estados Unidos a niveles masivos, porque no se les puede ofrecer nada" en su país de origen (Wallace 2018).

La erosión de la importancia de lo nacional se observa en Moronga (2018) a través de los esfuerzos que Zeledón y Aragón hacen para extirpar cualquier característica que los pueda señalar como salvadoreños ${ }^{12}$. Por una parte, la paranoia que experimentan está justificada por el hecho de que, en el campus estadounidense donde trabajan, los centroamericanos están sujetos a mayor vigilancia. A la vez, los antecedentes políticos de los dos no son la única razón que tienen para preocuparse. Sin nunca darse cuenta de ello, Zeledón y Aragón pierden sus puestos de trabajo - uno como conductor de bus escolar y otro como profesor universitario - a causa de su incapacidad de acatar (o siquiera comprender) las normas de conducta basadas en la visión anglosajona del género y la sexualidad. La preocupación por cómo los salvadoreños pueden inscribirse dentro del modelo cultural estadounidense y qué parte de su identidad centroamericana tendrán que sacrificar para lograrlo constituye uno de los temas que Castellanos Moya había explorado en El asco (1997) y retomó en Moronga (2011), enfocándose en sus aspectos aún más siniestros.

Como anota María del Pilar Vila, los medios culturales e intelectuales de Centroamérica se han afanado por "cancelar la marginalidad de la región partiendo de la idea de que es preciso revisar y reconsiderar la historia política y cultural focalizando su atención, de modo especial, en el discurso literario" $(2014,554)$. Es innegable la contribución de Horacio Castellanos Moya a este proyecto crucial dado que es precisamente a través de su obra literaria que muchos lectores que residen fuera de Centroamérica se aproximan a la historia salvadoreña y a la producción cultural de la región. La faceta más importante del espacio que hallamos entre La sirvienta y el luchador (2011) y Moronga (2018) no es solo la información sobre las vidas de los personajes de estas obras que esclarece el significado de las dos novelas, sino la idea de la suma importancia de que se conozca y se entienda la totalidad de la historia del istmo.

12 Vemos aquí los ecos de El asco. Thomas Bernhard en San Salvador (1997), la novela cuyo protagonista, Edgardo Vega, hace enormes esfuerzos por disimular el hecho de ser salvadoreño en su vida en Canadá. En muchos sentidos, Aragón es una continuación literaria de Vega, tanto en lo que concierne su neuroticismo como en su manera de pensar y expresarse. 


\section{Bibliografía}

Barchino, Matías. "Del asco a la identidad nacional. La narrativa de Horacio Castellanos Moya." Centroamericana, No. 13 (2007): 5-22.

Basile, Teresa. "Memorias perturbadoras / memorias autocríticas: revisión de la izquierda revolucionaria en la narrativa de Horacio Castellanos Moya." Alter / Nativas: Latin American Cultural Studies Journal, No. 5 (2015): 1-30, https://kb.osu.edu/bitstream/handle/1811/81925/CLAS_AN_AU15_Basile_MemoriasPerturbadoras.pdf? sequence $=1$ \&isAllowed=y (consultada 18 de febrero de 2021)

Bezhanova, Olga. "Horacio Castellanos Moya's Moronga and the Narrative Destabilization of Neoliberal Mentality." Canadian Journal of Latin American and Caribbean Studies / Revue canadienne des études latino-américaines et caraïbes, No. 45.2 (2000): 212-26.

Bueler, Lois E. The Tested Woman Plot: Women's Choices, Men's Judgments, and the Shaping of Stories. Columbus: Ohio State UP, 2001.

Buschmann, Albrecht. "Horacio Castellanos Moya (Honduras, 1957)", en The Contemporary Spanish-American Novel: Bolaño and After, 118-26. Edición de Will H. Corral, Juan E. De Castro y Nicholas Birns. (pp.). London \& New York: Bloomsbury, 2013.

Calvento, Mariana. "Fundamentos teóricos del neoliberalismo: su vinculación con las temáticas sociales y sus efectos en América Latina." Convergencia: Revista de Ciencias Sociales, No. 41 (2006): 41-59.

Castellanos Moya, Horacio. Recuento de incertidumbres: cultura y transición en El Salvador. San Salvador: Ediciones Tendencias, 1993.

Castellanos Moya, Horacio. La sirvienta y el luchador. Buenos Aires: Tusquets Editores, 2011.

Castellanos Moya, Horacio. Moronga. Barcelona: Penguin Random House, 2018.

Castillo Fernández, Dídimo. “The New ‘De-globalization' Environment: A View from Latin America." Critical Sociology, No. 44.1 (2018): 3-10.

Coello Gutiérrez, Emiliano. "El discurso crítico sobre el cinismo en la novela centroamericana contemporánea. Bases para una lectura alternativa. Convivencia, No. 1 (2014): 31-55, http://www.cervantesvirtual.com/nd/ ark:/59851/bmcvm660 (consultada 21 de diciembre de 2020)

Cortez, Beatriz. Estética del cinismo. Pasión y desencanto en la literatura Centroamericana de posguerra. Guatemala: F\&G Editores, 2009. 
Cuéllar, Roberto. "The Legal Aid Heritage of Oscar Romero." En Archbishop Romero and Spiritual Leadership in the Modern World, 147-60. Edición de Rev. Robert S. Pelton. Lanham: Lexington Books, 2015.

Dardot, Pierre, Laval, Christian. The New Way of the World: On Neo-Liberal Society. Trad. Gregory Elliott. London: Verso, 2013.

Dudley, Steven S. "Drug Trafficking Organizations in Central America: Transportistas, Mexican Cartels and Maras." En Working Paper Series on U.S.-Mexico Security Collaboration. Organized Crime in Central Ameri$c a, 8-61$. Edición de Cynthia J. Arnson y Eric Olson. Washington, DC: Woodrow Wilson Center for International Scholars, 2011.

Escamilla, José Luis. El protagonista en la novela de posguerra centroamericana: Desterritorializado, híbrido y fragmentado. San Salvador: Editorial Universidad Don Bosco, 2011.

Escobedo, María. "Horacio Castellanos Moya: 'Los mitos de la libertad son un privilegio de las élites." Cuadernos hispanoamericanos, No. 730 (2011): 131-8.

Fernández Hall, Lilian. "Horacio Castellanos Moya. 'El patriotismo es una estupidez generalizada en todo el planeta." Letralia: Tierra de Letras, No. 14. 217 (2009), https://letralia.com/217/entrevistas01.htm (consultada 27 de diciembre de 2020)

Galindo-Doucette, Evelyn. "La imaginación global y la ética cosmopolita en $E l$ asco de Horacio Castellanos Moya." Realidad: Revista de Ciencias Sociales y Humanidades, No. 134 (2012): 553-65.

Hirsch, E. D. Validity in Interpretation. New Haven: Yale UP, 1967.

Jossa, Emanuela. "Horacio Castellanos Moya, Moronga." Altre Modernità, No. 21 (2019): 346-49, https://riviste.unimi.it/index.php/AMonline/article/ view/11688/10984 (consultada 2 de noviembre de 2020)

Kampwirth, Karen. Women and Guerrilla Movements: El Salvador, Chiapas, Cuba. University Park, PA: Pennsylvania State UP, 2010.

Kokotovic, Misha. "Neoliberal Noir: Contemporary Central American Crime Fiction as Social Criticism." Clues: A Journal of Detection, No. 24.3 (2006): $15-29$.

Leary, John Patrick. Keywords: The New Language of Capitalism. Chicago: Haymarket Books, 2018.

Mackenbach, Werner \& Ortiz Wallner, Alexandra. "(De)formaciones: violencia y narrativa en Centroamérica." Iberoamericana, No. 7.32 (2008): 81-97. 
Mansilla, H. C. F. "Los iluminados y sus sombras. Crítica de la guerrilla latinoamericana. 1960-1975." Nueva Sociedad, No. 105 (1990):118-29.

Manwaring, Max G. A Contemporary Challenge to State Sovereignty: Gangs and Other Illicit Transnational Criminal Organizations in Central America, El Salvador, Mexico, Jamaica, and Brazil. Carlisle, PA: Strategic Studies Institute, 2007.

Musalo, Karen. "El Salvador - A Peace Worse than War: Violence, Gender and a Failed Legal Response." Yale Journal of Law and Feminism, No. 30.3 (2018): 1-97. https://digitalcommons.law.yale.edu/cgi/viewcontent.cgi?article $=1383 \&$ context $=y j l f$ (consultada 20 de abril de 2021)

Obinna, Denise N. "Seeking Sanctuary: Violence Against Women in El Salvador, Honduras, and Guatemala." Violence Against Women, No.27.6-7(2021): 80627. https://journals.sagepub.com/doi/metrics/10.1177/1077801220913633 (consultada 22 de abril de 2021)

Ortiz Wallner, Alexandra. "El arte de ficcionar en Horacio Castellanos Moya. Cultura. Revista de la Secretaría de Literatura de El Salvador, No. 101 (2009): 191-202.

Perkowska, Magdalena, Zavala, Oswaldo. "Introducción: la tiranía de la ficción, la libertad de la ficción." En Tiranas ficciones: poética y política de la escritura en la obra de Horacio castellanos Moya. Edición de Magdalena Perkowska y Oswaldo Zavala. Pittsburgh: Instituto Internacional de Literatura Iberoamericana, 2018.

Perkowska, Magdalena. "La infamia de las historias y la ética de la escritura en la novela centroamericana contemporánea." Istmo, No. 22 (2011): 1-25. http://istmo.denison.edu/n22/articulos/24_perkowska_magdalena_form. pdf (consultada 18 de abril de 2021)

Portelli, Alessandro. "Sobre los usos de la memoria: memoria-monumento, memoria-involuntaria, memoria perturbadora." Sociohistórica, No. 32.2 (2013). http://www.sociohistorica.fahce.unlp.edu.ar (consultada 23 de octubre de 2020)

Quirós, Daniel. “'Ahora creo sólo en lo que cargo entre las bolsas': la política del cinismo en la posguerra centroamericana." Istmo: Revista virtual de estudios literarios y culturales centroamericanos, No. 21 (2010). http:// istmo.denison.edu/n21/proyectos/3-quiros_daniel_form.pdf (consultada 2 de enero de 2021)

Rodríguez Freire, Raúl. "Entrevista con Horacio Castellanos Moya." Hispamérica: revista de literatura, No. 40.118 (2011): 57-70. 
Rojas, Margarita G. \& Ovares, Flora. "La sirvienta y el luchador. Una interpretación.” Revista Letras, No. 63 (2018). https://www.revistas.una.ac.cr/index. php/letras/article/view/10909/13747 (consultada 29 de enero de 2021)

Sáenz Leandro, Ronald Andrés. "El eterno retorno a la diáspora de la memoria: Moronga de Horacio Castellanos Moya." Mitologías Hoy, No. 17 (2018): 345-9.

Salinas Figueredo, Darío. "Democratic Governability in Latin America: Limits and Possibilities in the Context of Neoliberal Domination." En Imperialism, Neoliberalism and Social Struggles in Latin America, 85-102. Edición de R. A. Dello Buono y J. B. Lara. Boston, MA: Brill, 2007.

Sarmiento, Ignacio. "Comunidad y catástrofe en la narrativa salvadoreña contemporánea: Horacio Castellanos Moya, Claudia Hernández y Mauricio Orellana." Transmodernity: Journal of Peripheral Cultural Production of the Luso-Hispanic World, No. 6.1 (2016): 16-34. https://escholarship.org/ uc/item/1fh7d715 (consultada 12 de febrero de 2021)

Seoane, Mercedes Elena. ¿¿Dé qué hablamos cuando hablamos de desencanto?” En La violencia como marco interpretativo de la investigación literaria. Una mirada pluridisciplinar a la narrativa hispanoamericana contemporánea, 81-98. Edición de Matei Chihaia. Tübingen: Narr Francke, 2019.

Sprenkels, Ralph. After Insurgency: Revolution and Electoral Politics in El Salvador.

Notre Dame: U of Notre Dame P, 2018.

Ventura, Patricia. Neoliberal Culture: Living with American Neoliberalism. Farnham / Burlington: Ashgate, 2012.

Vides, Méndez. "Cataclismos cotidianos y la caída de los pequeños héroes en la obra de Horacio Castellanos Moya." En Horacio Castellanos Moya. El diablo en el espejo, 21-30. Edición de María del Carmen Caña Jiménez and Vinodh Venkatesh. Valencia: Albatros Editores, 2016.

Vila, María del Pilar. "Las ilusiones perdidas: narrar la violencia. Acercamientos a la obra de Horacio Castellanos Moya." Revista Iberoamericana, No 80.227 (2014): 553-70.

Wallace, Arturo. "Horacio Castellanos Moya, escritor salvadoreño: 'Los centroamericanos no son Estados fallidos, son Estados tullidos.'” BBC News, (22 de mayo de 2018), https://www.bbc.com/mundo/noticias-44154694 (consultada 22 de febrero de 2021). 
